\title{
ANALISIS SALURAN PEMASARAN KERIPIK GADUNG (Dioscorea hispida L.) PADA USAHA HOME INDUSTRY DUA PUTRA JAYA DI KABUPATEN JOMBANG
}

\author{
Muhammad Amir Ma'sum¹, Umi Kulsum Nur Qurmariah² \\ ${ }_{1,2}$ Program Studi Agribisnis. Fakultas Pertanian. Universitas KH. A. Wahab \\ Hasbullah. Jombang \\ ${ }^{1}$ E-mail:mamirmasum@gmail.com
}

\begin{abstract}
This study aims to determine the form of marketing channels, marketing margins, share of the price received by producers and marketing efficiency of gadung chips in the "Dua Putra Jaya" home industry in Jombang Regency. This study uses a quantitative descriptive method. Determination of sampling is done purposively. Respondents include producers, retailers, collectors, and consumers. Data were obtained from direct observation in the field through interviews, distributing questionnaires and tracing. The results showed that the marketing channel for Gadung chips "Dua Putra Jaya" consists of three marketing channels, namely; zero-level channels consist of producers $\square$ consumers, Level 1 channels consist of producers $\square$ retailers $\square$ consumers; Level 2 marketing channels consist of producers $\square$ collectors $\square$ retailers $\square$ consumers. The total margin on the zero level channel is non existent, the level 1 marketing channel is IDR 20,000 and the level 2 marketing channel is IDR 20,000. The share of the price received by on the zero level channel does not exist, the price share on the level 1 channel is $75 \%$; while the channel level 2 is $55.5 \%$. There is no efficiency value in the zero level marketing channel, the marketing channel level 1 is $31.6 \%$ and the marketing channel level 2 is $35.5 \%$, so that it can be seen that the marketing channel in channel one is more efficient because of the marketing costs incurred in channel one. less first.
\end{abstract}

Keywords: marketing channel, marketing margin, Share of price received by producers, Marketing efficiency of gadung chips.

\section{ABSTRAK}

Penelitian ini bertujuan untuk mengetahui bentuk saluran pemasaran, margin pemasaran, bagian harga yang diterima produsen dan efisiensi pemasaran keripik gadung pada home industry "Dua Putra Jaya" di Kabupaten Jombang. Penelitian ini menggunakan metode deskriptif kuantitatif. Penentuan sampling dilakukan secara purpossive. Responden meliputi produsen, pengecer, pengumpul, dan konsumen. Data diperoleh dari observasi langsung di lapangan melalui wawancara, penyebaran angket dan tracing. Hasil penelitian menunjukan bahwa saluran pemasaran keripik Gadung " Dua Putra Jaya” terdiri atas atas tiga saluran pemasaran yaitu; saluran tingkat nol terdiri atas produsen $\rightarrow$ konsumen, Saluran tingkat 1 terdiri atas produsen $\rightarrow$ pengecer $\rightarrow$ konsumen; saluran pemasaran tingkat 2 terdiri atas produsen $\rightarrow$ pengumpul $\rightarrow$ pengecer $\rightarrow$ konsumen. Margin total pada saluran tingkat nol tidak ada, saluran pemasaran tingkat 1 sebesar Rp 20.000 dan saluran pemasaran tingkat 2 sebesar Rp 20.000. Bagian harga yang 
diterima oleh pada saluran tingkat nol tidak ada, bagian harga pada saluran tingkat 1 sebesar $75 \%$; sedangkan pada saluran tingkat 2 sebesar $55,5 \%$. Nilai efisiensi pada saluran pemasaran tingkat nol tidak ada, pada saluran pemasaran tingkat 1 sebesar $31,6 \%$ dan pada saluran pemasaran tingkat 2 sebesar $35,5 \%$,sehinga dapat dilihat bahwa saluran pemasaran pada saluran satu lebih efisien karena biaya pemasaran yang dikeluarkan pada saluran pertama lebih sedikit.

\section{Kata kunci: Saluran pemasaran, Margin pemasaran, Bagian harga yang diterima produsen, Efisiensi pemasaran keripik gadung.}

\section{PENDAHULUAN}

Agribisnis dan agroindustri merupakan pendekatan yang ditempuh untuk pengembangan pertanian industri pada masa yang akan datang karena industri pengolahan hasil pertanian (agroindustri) yang ditangani secara utuh, mulai dari proses produksi, mengolah hasil, pemasaran, dan aktivitas lain yang berkaitan dengan kegiatan pertanian (agribisnis) bukan saja mampu sebagai sumber pertumbuhan baru bagi sektor pertanian tetapi juga mampu menyerap banyak tenaga kerja dan meningkatkan nilai tambah (Soekartawi, 1991).

Home industry adalah suatu unit usaha/perusahaan dalam skala kecil yang bergerak dalam bidang industri tertentu. Biasanya usaha ini hanya menggunakan satu atau dua rumah sebagai pusat produksi, administrasi dan pemasaran sekaligus secara bersamaan. Bila dilihat dari modal usaha dan jumlah tenaga yang diserap tentu lebih sedikit daripada perusahaan-perusahaan besar pada umumnya (Fitria, 2013).

Pemasaran merupakan proses yang harus dilalui petani sebagai produsen untuk menyalurkan produknya hingga sampai ke tangan konsumen. Seringkali dijumpai adanya rantai pemasaran yang panjang dengan banyak pelaku pemasaran yang harus diambil oleh para pelaku pemasaran yang terlibat. Akibatnya, balas jasa yang harus diambil oleh para pelaku pemasaran menjadi besar yang akhirnya akan mempengaruhi tingkat harga. Hal ini mengindikasikan bahwa sistem pemasaran yang terjadi sebelum efisien (Mubyarto, 1989).

Gadung merupakan perdu memanjat yang tingginya dapat mencapai 5-10 m.Batangnya bulat, berbulu dan berduri yang tersebar sepanjang batang dan tangkai daun. Umbinya bulat diliputi rambut akar yang besar dan kaku, kulit umbi berwarna gading atau coklat muda, daging umbinya berwarna putih gading atau kuning.umbinya muncul dekat permukaan tanah. Dapat dibedakan dari jenis-jenis dioscorea lainnya karena daunnya merupakan daun majemuk terdiri dari 3 helai daun. Bunga tersusun dalam ketiak daun, berbulit, berbulu, dan jarang sekali dijumpai (Rukmana, 2001).

Umbi gadung merupakan salah satu sumber pangan berkarbohidrat tinggi. Gadung dapat memenuhi kebutuhan energi tubuh. Karbohidrat dalam gadung didominasi oleh pati. Selain memiliki kandungan karbohidrat juga mengandung racun sianida yang dapat menyebabkan keracunan dan mematikan. Sehingga perlu dilakukan beberapa proses untuk menghilangkan kandungan residu HCN atau meminimalkan sehingga umbi gadung menjadi aman dan layak untuk dikonsumsi (Kurnia, 2002). Kandungan sianida 50 ppm bahan masih aman untuk dikonsumsi (Winarno, 1995).

Keripik gadung adalah makanan cemilan atau makanan ringan yang dibuat dari umbi gadung. Proses produksi keripik gadung ini sangat panjang dan rumit hingga sampai menjadi keripik gadung yang siap untuk dikonsumsi . Proses pengolahan keripik gadung sendiri terbilang sangat lama mulai dari proses pengupasan, pencucian, perebusan, dan penjemuran. Pejemuran keripik gadung 
sendiri sendiri bisa dua hari bahkan lebih tergantung cuaca dan bila sudah kering keripik sudah bisa digoreng atau siap untuk dikonsumsi.

Home Industry di Dua Putra Jaya Dusun Kedungwatu Desa Made Kecamatan Kudu Kabupaten Jombang, masih menghadapi permasalahan proses pemasaran seperti kesulitan dalam mencapai tujuan pasar, sebagian besar makanan tradisional khususnya yang diperdagangkan secara tradisional untuk memenuhi permintaan pasar lokal dan hanya sebagian kecil dipasarkan diluar daerah jombang,diantaranya kota Gresik dan Surabaya. Namun disini rantai pemasaran yang banyak menyertakan lembaga pemasaran dapat menyababkan kecilnya persentase perbandingan yang diterima produsen dengan harga yang dibayarkan oleh konsumen (producer's share).

Pemasaran keripik gadung di home industry Dua Putra Jaya ini menunjukan perbedaan harga yang relatif besar antara jumlah yang dibayarkan oleh konsumen dengan jumlah harga yang ditentukan oleh produsen yang tentunya berpengaruh terhadap margin pemasaran. Kegiatan pemasaran dalam home industry keripik gadung dua putra jaya mempunyai peranan penting terhadap kelangsungan usaha. Oleh karena itu, perlu dilakukan penelitian analisis saluran pemasaran keripik gadung di home industry Dua Putra Jaya di Kabupaten Jombang.

\section{METODE PENELITIAN}

Penelitian ini dilakukan pada home industry keripik gadung Dua Putra Jaya di Dusun Kedungwatu Desa Made Kecamatan Kudu Kabupaten Jombang. Penentuan lokasi dilakukan secara sengaja (purpossive) dengan pertimbangan bahwa home industry Dua Putra Jaya merupakan pioner usaha kri[pik gadung di desa Made kecamatan Kudu Kabupaten Jombang. Objek dalam penelitian ini adalah Keripik Gadung pada Dua Putra Jaya. Lingkup pemasaran keripik gadung ini di Kabupaten Jombang dan luar daerah seperti Gresik dan Surabaya.

Penentuan responden dilakukan secara sengaja(purposive), dengan mewawancarai pimpinan industri dan tenaga kerja. Penentuan responden pedagang dilakukan dengan menggunakan metode penjajakn (Tracing Sampling) yaitu pengambilan sampel berdasarkan informasi dari produsen.

Metode pengumpulan data yang dilakukan dalam peneltian ini terdiri atas data primer dan data sekunder. Data primer merupakan data yang diperoleh melalui observasi dan wawancara langsung dengan responden, yaitu itu pemilik home industry dengan kuesioner. Data sekunder diperoleh dari instansi terkait dan literatur yang relevan untuk menunjang penelitan ini (Anwar dkk 2018).

Analisis yang digunakan yaitu analisis deskriptif, analisis saluran pemasaran analisis margin pemasaran, analisis bagian harga yang diterima produsen dan analisis efisiensi pemasaran.

1. Margin Pemasaran

Menghitung besar margin pemasaran dihitung dengan menggunakan rumus sebagai berikut (Anindita, 2004).

Keterangan :

$$
\mathrm{Mm}-\mathrm{Hk}-\mathrm{Hp}
$$

M : Margin Pemasaran (Rp)

$\mathrm{Hk} \quad$ : Harga di tingkat konsumen (Rp)

$\mathrm{Hp} \quad$ : Harga ditingkat produsen (Rp)

$\mathrm{Pk} \quad$ : Harga di tingkat konsumen (Rp)

Margin total pemasaran (MT) adalah jumlah margin dari semua lembaga pemasaran yang terilibat dalam pemasaran Keripik Gadung "Dua Putra Jaya" dihitung dengan menggunakan rumus (Anandita,2004) :

$$
\mathbf{M t}=\mathbf{M}_{1}+\mathbf{M}_{2}+\mathbf{M}_{3} \ldots+\mathbf{M}_{\mathbf{n}}
$$


Keterangan :

Mt : Margin Total Pemasaran (Rp)

$M_{1} \quad$ : Margin Pemasaran Pada pedagang Pengumpul (Rp)

$\mathrm{M}_{2} \quad$ : Margin Pemasaran Pada Pedagang Pengecer (Rp)

2. Bagian harga yang diterima produsen (Producer's Share)

Mengetahui bagian harga yang diterima oleh produsen dari harga yang dibayarkan oleh konsumen akhir dapat digunakan rumus (Swastha,2002) :

Keterangan :

$$
s f-\frac{p f}{p r} X 100 \%
$$

Sf : Bagian harga yang di terima produsen (\%)

$\mathrm{Pf}$ : Harga di tingkat produsen $(\mathrm{Rp})$

$\operatorname{Pr}$ : Harga ditingkat produsen (Rp)

3. Efisiensi pemasaran

Mengetahui pemasaran keripik gadung "Dua Putra Jaya" dari produsen atau pedagang pengecer I ke pengumpul II dan pedagang pengecer III digunakan rumus (Soekartawi,2002).

$$
E \boldsymbol{P}=\frac{B p}{N p} X 100 \%
$$

Keterangan :

$\begin{array}{ll}\mathrm{Ep} & \text { : Efisiensi Pemasaran (\%) } \\ \mathrm{Bp} & \text { : Biaya Pemasaran (Rp) } \\ \mathrm{Hp} & \text { : Nilai produk yang dipasarkan }(\mathrm{Rp})\end{array}$

\section{HASIL DAN PEMBAHASAN}

Usaha Keripik Gadung merupakan salah satu industri rumahan yang ada di Dusun Kedungwatu Desa Made Kecamatan Kudu Kabupaten Jombang. Terdapat salah satu usaha Keripik Gadung yang bernama Dua Putra Jaya berdiri sejak tahun 1999 sampai dengan sakarang di bawah pimpinan Bapak Sunaryo. Usaha ini bergerak di bidang produksi keripik gadung yang telah dikenal oleh masyarakat kabupaten Jombang maupun di kalangan masyarakat luar daerah. Agroindustri ini mengolah produk primer menjadi produk sekunder yaitu mengolah umbi gadung menjadi keripik gadung.

\section{Struktur Organisasi}

Struktur organisasi home industry disajikan pada Gambar 3.

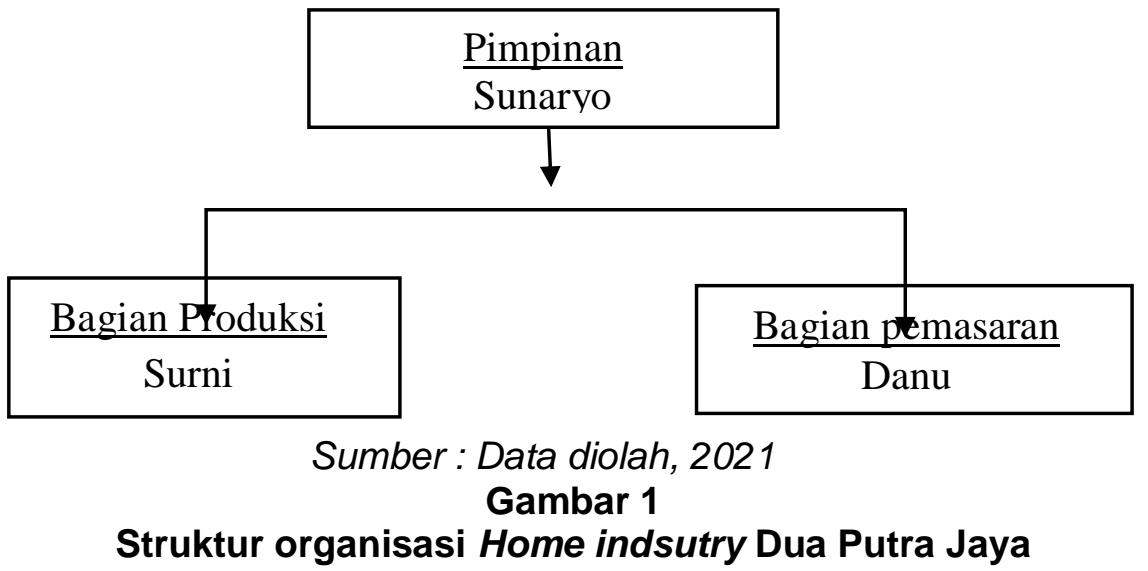




\section{Pimpinan}

Pimpinan bertanggung jawab langsung terhadap jalannya operasional usaha pembuatan Keripik Gadung secara keseluruhan. Pimpinan usaha home industry adalah bapak Sunaryo selaku pemilik yang bertugas mengawasi seluruh proses produksi Keripik Gadung dari awal sampai proses akhir dan memantau proses pemasaran. Pimpianan home industry Dua Putra jaya disajikan pada Gambar 4.

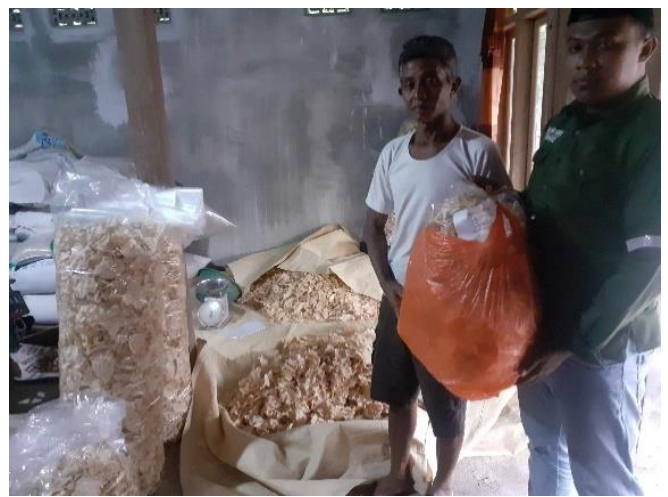

Sumber: Dokumentasi Pribadi, 2021

Gambar 2

Pimpinan home industry Dua Putra jaya

\section{B.Karakteristik Responden}

Berdasarkan data yang dipreroleh dari hasil penelitian langsung dengan produsen keripik gadung dan pengumpul dan pengecer, diketahui karakteristik responden dalam penelitian adalah umur responden, tingkat pendidikan dan pengalaman indsutri

Tabel 1. Rata-rata Umur responden produsen, pedagang Keripik Gadung Dua Putra Jaya, 2021

\begin{tabular}{lll}
\hline No & Responden & Umur (Tahun) \\
\hline 1. & Produsen & 54 \\
\hline 2. & Pengecer I & 48 \\
\hline 3. & Pengumpul II & 45 \\
\hline 4. & Pengecer II & 50
\end{tabular}

Sumber : Data Primer yang diolah, 2021

Umur Responden. Umur dapat mempengaruhi kemampuan fisik, cara berpikir dan sikapnya dalam pengambilan keputusan. Responden yang berumur lebih tua memiliki kemampuan fisik lebih lemah tetapi lebih banyak pengalaman dan sangat berhati-hati dalam mengambil keputusan.

Tabel 2. .Rata-rata Tingkat Pendidikan Responden Produsen dan Pedagang Keripik Gadung, Dua Putra Jaya Tahun, 2021.

No Responden

1. Produsen SD

2. Pengecer I SMP

3. Pengumpul II SMP

4. Pengecer II SD

Sumber : Data Primer yang diolah, 2021

Tingkat Pendidikan Responden. Tingkat pendidikan merupakan faktor yang sangat mendukung kemampuan berpikir maupun berkerja setiap individu dalam 
melakukan usaha. Semakin tinggi tingkat pendidikan yang dimiliki produsen makan akan mudah menerima inovasi untuk mengembangkan usahanya dibandingkan yang memiliki pendidikan rendah.

Tabel 3. Rata-rata Pengalaman Berindustri Responden Keripik gadung Dua Putra Jaya, tahun 2021.

No Responden

\section{Pengalaman Berindustri} (Tahun)

1. Produsen 20

2. Pengecer I 10

3. Pengumpul II 17

4. Pengecer II 9

Sumber: Data Primer yang diolah, 2021

Pengalaman Berindustri. Pengalaman berindustri juga merupakan faktor penentu keberhasilan responden dalam mengelola usahanya.tabel 3 responden telah banyak memeliki pengalaman berindustri dalam mengelola usahanya.

\section{C.Saluran Pemasaran keripik Gadung}

\section{Bagian Produksi}

Bagian produksi menangani proses pembuatan keripik gadung secara keseluruhan dari awal proses produksi sampai proses pengemasan. Pada bagian ini dibantu tiga tenaga kerja.

\section{Bagian Pemasaran}

Bagian pemasaran bertugas mengetahui keadaan pasar, permintaan produk keripik gadung, mengecek serta mengantarkan produk keripik gadung ke pasar. Proses pengemasan keripik gadung yang siap dipasarkan disajikan pada Gambar 5.

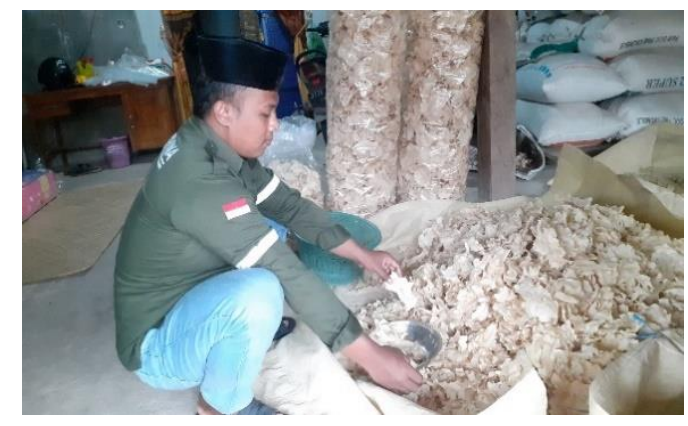

Sumber: Dokumentasi Pribadi, 2021

Gambar 3

\section{Proses Produksi}

\section{Proses pemasaran keripik gadung}

Proses produksi adalah rangkaain proses pengolahan bahan baku menggunakan peralatan dan tenaga kerja sampai menghasilkan produk. Proses produksi usaha keripik gadung "Dua Putra Jaya" menentukan jumlah produk yang di hasilkan. Proses produksi keripik gadung dari umbi gadung sampai siap konsumsi membutuhkan waktu satu minggu,tergantung ketersediaan bahan baku dan cuaca. Proses produksi keripik gadung disajikan pada Gambar 6. 


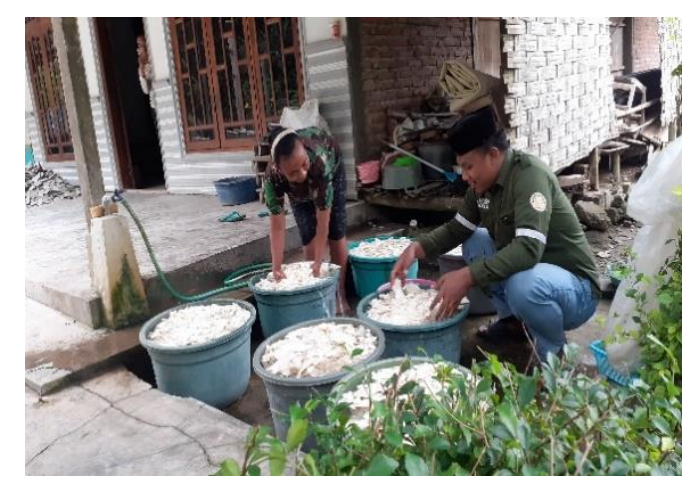

Sumber: Dokumentasi pribadi, 2021

\section{Gambar 4}

Proses produksi keripik gadung

Proses produksi usaha "Dua Putra Jaya" memproduksi keripik gadung dalam bentuk kemasan plastik kemasan 1.000 gr. Volume produksi setiap minggunya berbeda tergantung ketersedian bahan baku yang ada dalam satu kali produksi. Bahan baku yang diperlukan dalam satu kali produksi keripik gadung di home industry Dua putra jaya disajikan di tabel 1. Dalam satu kali proses produksi dilakukan satu minggu sekali, 4 kali kali dalam satu bulan.

Proses produksi kripik gadung disajikan pada Gambar 7.

Diagram alur pembuatan keripik gadung

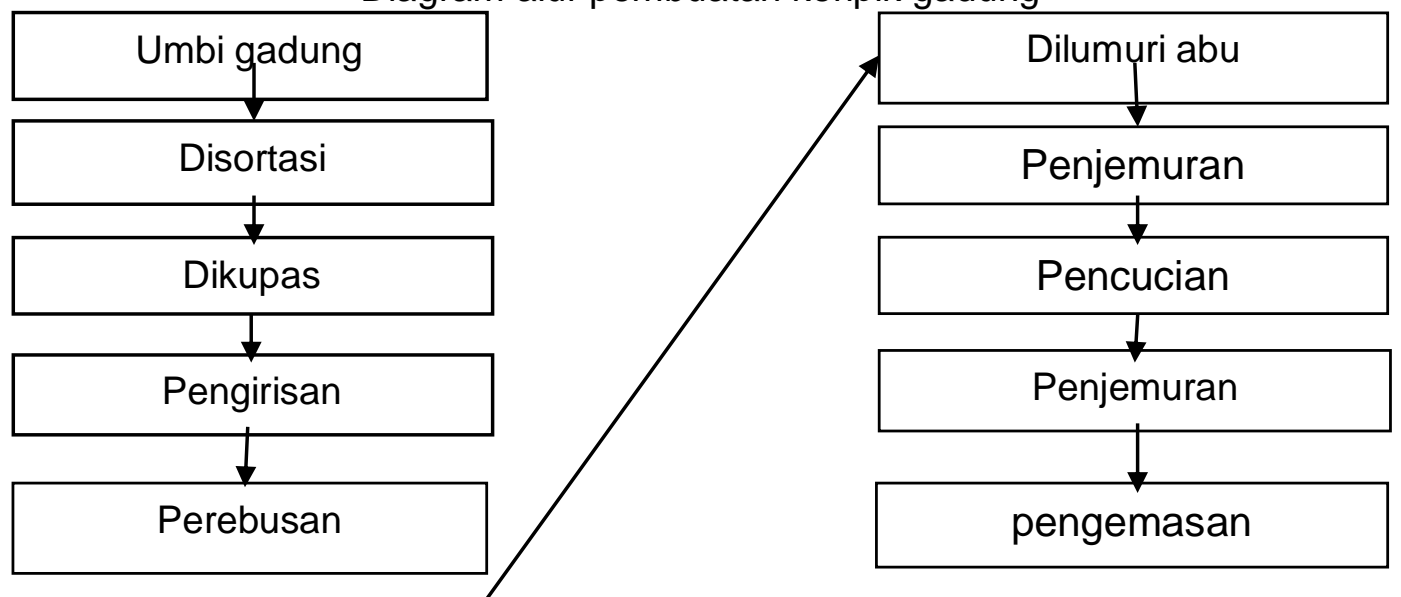

Sumber: Data diolah, 2021

Gambar 5

Alur pembuatan keripik gadung

Biaya bahan baku dan pelengkap yang digunakan pada sproses produksi keripik gadung, usaha Dua Putra jaya. Dalam satu kali produksi terlihat pada Tabel berikut

Tabel 4. Bahan Baku yang digunakan dalam satu kali produksi Keripik Gadung Dua Putra Jaya untuk bulan Mei, Tahun 2021.

\begin{tabular}{|c|c|c|}
\hline \multirow{2}{*}{$\frac{\text { Umbi Gadung (kg) }}{200 \mathrm{~kg}}$} & Kemasan(kg) & Jumla \\
\hline & $\begin{array}{l}500 \mathrm{gr} \\
1.000 \mathrm{gr}\end{array}$ & $\begin{array}{l}15 \mathrm{~kg} \\
15 \mathrm{~kg}\end{array}$ \\
\hline & Jumlah & $30 \mathrm{~kg}$ \\
\hline
\end{tabular}

Sumber: Data Primer yang diolah, 2021 Jumlah(kg) $15 \mathrm{~kg}$ $0 \mathrm{~kg}$ 
Tabel 4. Menunjukan bahwa untuk 200/kg umbi gadung basah menghasilkan $15 / \mathrm{kg}$ bungkus untuk kemasan 500/gr dan 15/kg bungkus untuk kemasan 1.000/gr yang siap dipasarkan dalam satu kali produksi, proses produksi dilakukan 4 kali dalam satu bulan. Besarnya biaya bahan dari kebutuhan bahan baku yang diperlukan dalam satu kali produksi ditampilkan pada Tabel 5.

Tabel 5. Biaya bahan baku dan pelengkap dalam pembuatan Keripik Gadung pada Usaha Dua Putra Jaya dalam satu kali produksi untuk bulan Mei ,tahun 2021.

\begin{tabular}{lllll}
\hline No & Bahan Baku & Jumlah & Harga (Rp) & Jumlah (Rp) \\
\hline 1. & Gadung & $\begin{array}{l}200 \\
\text { Kilogram }\end{array}$ & 1.300/krg & 260.000 \\
\hline 2. & Garam & 1 Bungkus & $9.000 / \mathrm{pcs}$ & 9.000 \\
\hline 3. & Abu & 4Kilogram & $50.000 / \mathrm{kg}$ & 200.000 \\
\hline 4. & Kayu & 1 per ikat & $50.000 / \mathrm{kt}$ & 50.000 \\
\hline 5. & Listrik & 7 Hari & $2.000 /$ jam & 14.000 \\
\hline 6. & Plastik & 1 Roll & $38.000 / \mathrm{rl}$ & 38.000 \\
\hline & & & Jumlah & 571.000 \\
\hline
\end{tabular}

Sumber: Data Primer yang diolah, 2021

Tabel 5. Menunjukan bahwa total biaya pembelian bahan baku dan bahan pelengkap dalam satu kali pembuatan keripik gadung usaha Dua Putra Jaya yang digunakan dalam satu kali produksi sebesar Rp. 571.000, dalam satu bulan 4 kali produksi sama dengan Rp.2.284.000. Bahan-bahan baku pembuatan keripik gadung diperoleh dari perkebunan sekitar dan luar daerah Kabupaten Jombang yaitu gunung wono, dari petani Nganjuk dan petani Bojonegoro.

Saluran Pemasaran. Berdasarkan hasil penelitian analisis pemasaran keripik gadung Dua Putra jaya RT. 04. RW. 01 Di Dua Putra jaya Dusun Kedungwatu Desa Made Kecamatan Kudu Kabupaten Jombang. Terdapat tiga saluran pemasaran.

Saluran pemasaran adalah rangkaian proses menyalurkan barang yang melibatkan beberapa lembaga pemasaran dari produsen hingga konsumen diamana sepanjang rantai pemasaran tersebut terjadi penambahan nilai produk (Kotler, 2014).

Saluran pemasaran Tingkat Nol. Pada saluran pemasaran tingkat nol terjadi proses saluran pemasaran yang melibatkan antara produsen dan konsumen. Pola saluran pemasaran tingkat nol ini menunjukan pola saluran pemasaran terpendek, dimana hanya melibatkan dua lembaga pemasaran yakni produsen dan konsumen. Saluran pemasaran tingkat nol mempunyai kelebihan, yaitu harga atau keuntungan yang diterima produsen jauh lebih besar. Namun kekurangannya jumlah produk yang terjual hanya dalam jumlah kecil dan konsumen hanya tetangga-tetangga sekitar rumah bapak Sunaryo dan daerah sekitar.Pemasaran produk dari produsen langsung ke konsumen akhir. Dengan harga keripik gadung Rp.35.000/kg, untuk kemasan 1.000 gr. Sistem pembayaran tunai.

Gambar menjelaskan saluran pemasaran pada Tingkat Nol.

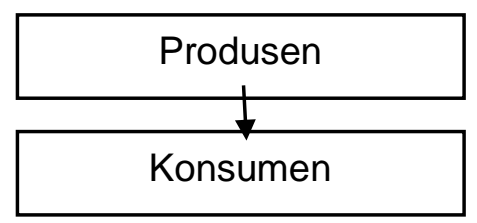

Sumber: Data diolah, 2021 


\section{Gambar 6 \\ Saluran Pemasaran Tingkat nol.}

Saluran Pemasaran Tingkat I .Pada saluran pemasaran tingkat I merupakan saluran pemasaran yang hampir melibatkan seluruh lembaga pemasaran dari produsen sampai konsumen akhir. Saluran pemasaran ini adalah saluran pemasaran sedang, pemasaran dimulai dari produsen ke pengecer dan konsumen akhir. Saluran pemasaran ini tergolong saluaran pemasaran sedang. Pemasaran ini dimulai dari pedagang pengecer yang mendatangi langsung ke produsen untuk membeli keripik gadung, dalam satu kali produksi ( 1 minggu sekali produksi). Harga yang diterima pengecer dari produsen keripik gadung dengan kemasan $1.000 \mathrm{gr}$ sebesar Rp. 60.000, sistem pembayaran tunai dan pengecer menjual ke konsumen akhir dengan harga sebesar Rp.80.000 untuk kemasan $1.000 \mathrm{gr}$ dan pada saluran ini keripik gadung sudah siap untuk dikonsumsi atau sudah menjadi kerupuk gadung.

Gambar menjelaskan saluran pemasaran pada Tingkat I

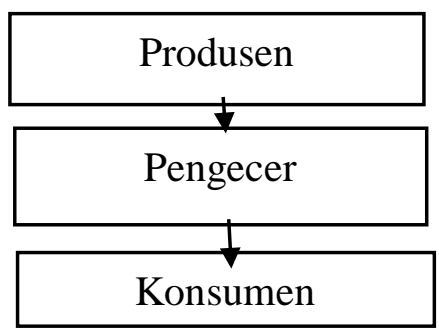

Sumber: Data diolah, 2021

Gambar 7

Saluran Tingkat I

Saluran pemasaran Tingkat II. merupakan saluran pemasaran yang paling panjang dan melibatkan seluruh lembaga dari produsen sampai konsumen akhir. Saluran pemasaran satu ini sering juga saluran pemasaran panjang. Pemasaran dimulai dari produsen, pengumpul, pengecer, dan konsumen akhir, pengambilan keripik gadung dilakukan pengumpul langsung ke produsen sebanyak $200 \mathrm{~kg}$ dan pengecer mengambil dari pengumpul secara langsung.Harga yang diterima pengumpul dari produsen sebesar Rp. $25.000 / \mathrm{kg}$, harga yang diterima pengecer dari pengumpul sebesar Rp.35.000/kg dan harga yang diterima konsumen dari pengecer sebesar Rp.45.000/kg, dengan kemasan $1.000 \mathrm{gr}$. Sistem pembayaran tunai.

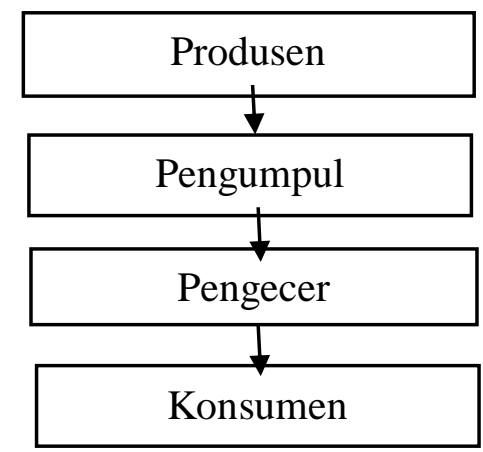

Sumber: Data diolah, 2021

Gambar 8 


\section{Saluran Pemasaran Tingkat II}

Biaya Pemasaran. Biaya pemasaran keripik gadung pada home indsutry Dua putra jaya yang dikeluarkan pada setiap lembaga pemasaran meliputi: untuk saluran pemasaran tingkat tingkat nol tidak ada biaya pemasaran karena pembilian langsung ke produsen, untuk saluran pemasaran tingkat I meliputi biaya minyak goreng sebesar Rp 15.000, bensin Rp 10.000, plastik Rp 200 dan stiker Rp 1.00 mempunyai biaya total pemasaran sebesar Rp 25.300 berupa keripik matang dan untuk saluran pemasaran tingkat II meliputi biaya pengangkutan Rp 100.000, plastik Rp 40.000 dan stiker Rp 20.000 mempunyai total biaya pemasaran sebesar Rp 160.000 berupa keripik mentah.

\section{Margin Pemasaran Keripik Gadung}

Margin pemasaran pada setiap lembaga pemasaran berbeda-beda baik pada saluaran tingkat nol, saluran tingkat pertama maupun saluran tingkat kedua. Pada saluran pemasaran tingkat nol nilai margin pemasaran pada saluran tingkat nol adalah Rp.0, karena hanya melibatkan produsen dan konsumen.

Tabel 6. Margin pemasaran keripik gadung pada saluran pemasaran tingkat pertama, bulan Mei, Tahun 2021

\begin{tabular}{llrrl}
\hline No & $\begin{array}{c}\text { Produsen/lembaga } \\
\text { pemasaran }\end{array}$ & kemasan & $\begin{array}{l}\text { Harga } \\
\text { Rp/bks }\end{array}$ & $\begin{array}{l}\text { Margin } \\
\text { pemasaran(Rp) }\end{array}$ \\
\hline 1. & Produsen & $1.000 \mathrm{gr}$ & 60.000 & \\
\hline 2. & Pengecer & $1.000 \mathrm{gr}$ & 80.000 & 20.000 \\
\hline & Margin total & & & 20.000 \\
\hline
\end{tabular}

Sumber : Data Primer yang diolah, 2021

Tabel 6. Menunjukan bahwa margin pemasaran keripik gadung pada saluran pemasaran tingkat pertama produsen menjual keripik gadung ke pengecer dengan harga ditingkat produsen sebesar $\mathrm{Rp} 60.000$ dan harga ditingkat pengecer sebesar Rp 80.000 untuk kemasan 1.000 gr, maka diperoleh margin pemasaran sebesar Rp 20.000 .

Tabel 7. Margin pemasaran keripik gadung pada saluran pemasaran tingkat kedua , bulan Mei, Tahun 2021

\begin{tabular}{lllrl}
\hline No & $\begin{array}{l}\text { Produsen/lembaga } \\
\text { pemasaran }\end{array}$ & kemasan & $\begin{array}{c}\text { Harga } \\
\text { Rp/bks }\end{array}$ & $\begin{array}{c}\text { Margin } \\
\text { pemasaran(Rp) }\end{array}$ \\
\hline 1. & Produsen & $1.000 \mathrm{gr}$ & 25.000 & \\
\hline 2. & Pengumpul & $1.000 \mathrm{gr}$ & 35.000 & 10.000 \\
\hline 3. & Pengecer & $1.000 \mathrm{gr}$ & 45.000 & 10.000 \\
\hline & Margin total & & & 20.000 \\
\hline
\end{tabular}

Sumber : Data Primer yang diolah, 2021

Tabel 7. Menunjukan bahwa margin pemasaran keripik gadung pada saluran pemasaran tingkat kedua terjadi proses pemasaran antara produsen, pengumpul, pengecer, dan konsumen. Masing- masing setiap lembaga pemasaran mendatangi langsung kepedagang untuk mengambil keripik gadung, margin pemasaran paling rendah pada tingkat pedagang pengumpul dengan margin pemasaran sebesar $\mathrm{Rp} 10.000$ dan pada saluran pemasaran tingkat pengecer sebesar Rp 10.000 untuk margin total sebesar Rp.20.000 untuk kemasan $1.000 \mathrm{gr}$. Hasil penelitian ini sejalan dengan penelitian yang telah dilakukan oleh (Husnidar, 2016). Bahwa saluaran pemasaran yang diteliti memiliki 
tiga saluran pemasaran yaitu saluran pemasaran tingkat nol, saluran pemasaran tingkat satu dan saluran pemasaran tingkat dua.

\section{E.Bagian Harga Yang DiTerima Produsen}

\section{Tabel 8. Bagian Harga Yang Diterima Produsen pada saluran Tingkat Nol,} saluran tingkat pertama dan saluran tingkat kedua.

\begin{tabular}{lllll}
\hline No & Uraian & Pf (Rp) & Pr (Rp) & Sf (\%) \\
\hline 1. & $\begin{array}{c}\text { Saluran Tingkat I } \\
\text { - Kemasan 1.000 gr }\end{array}$ & 60.000 & 80.000 & 75 \\
\hline 2. & $\begin{array}{l}\text { Saluran Tingkat III } \\
\text {-Kemasan 1.000 gr }\end{array}$ & 25.000 & 45.000 & 55,5 \\
\hline
\end{tabular}

Sumber: Data Primer yang diolah, 2021

Tabel 8. Menunjukan bahwa Bagian harga yang diterima oleh produsen keripik gadung Dua Putra jaya, pada saluran pemasaran tingkat nol tidak ada bagian harga yang diterima produsen karena hanya melalui proses pemasaran dari produsen ke konsumen langsung, pada saluran pemasan tingkat I bagian harga yang diterima produsen dengan harga ditingkat produsen sebesar $\mathrm{Rp}$ 60.000 dan harga ditingkat konsumen sebesar Rp 80.000 diperoleh bagian harga diterima produsen untuk saluran pemasaran tingkat I sebesar $75 \%$, untuk saluran pemasaran tingkat II bagian harga yang diterima produsen dengan harga ditingkat produsen sebesar Rp 25.000, harga ditingkat pengumpul sebesar Rp.35.000 dan ditingkat pengecer sebesar Rp 45.000 maka diperoleh bagian harga yang diterima produsen pada saluran pemasaran tingkat II sebesar Rp 55,5.

\section{E. Efisiensi Pemasaran Keripik Gadung}

Efisiensi pemasaran oleh setiap lembaga pemasaran dalam memasarkan keripik gadung dapat dilihat pada table 9.

Tabel 9. Efisiensi pemasaran Keripik Gadung Dua Putra jaya pada bulan Mei, 2021

\begin{tabular}{clccl}
\hline No & $\begin{array}{l}\text { Saluran } \\
\text { Pemasaran }\end{array}$ & Bp (Rp) & Np (Rp) & $\begin{array}{l}\text { Efisiensi Pemasaran } \\
(\%)\end{array}$ \\
\hline 1. & $\begin{array}{l}\text { Saluran Tingkat } \\
\text { II }\end{array}$ & 25.300 & 80.000 & 31,6 \\
\hline 2. & $\begin{array}{l}\text { Saluran Tingkat } \\
\text { II }\end{array}$ & 160.000 & 45.000 & 35,5 \\
\hline
\end{tabular}

Sumber : Data Primer yang diolah, 2021

Tabel 9. Menunjukan bahwa saluran pemasaran tingkat nol tidak mempunyai nilai efisiensi karena tidak ada biaya pemasaran, Sedangkan pada saluran pemasaran I efisiensi pemasaran sebesar 31,6 dan pada saluran pemasaran tingkat II efisensi pemasaran sebesar 35,5 maka saluran pemasaran dengan nilai efisiensi paling besar pada saluran pemasaran tingkat II dan saluran pemasaran yang sangat efisien terlihat pada saluran pemasaran tingkat I dengan efisiensi paling rendah yaitu sebesar $31,6 \%$.

\section{SIMPULAN}

Penelitian analisis saluran pemasaran keripik gadung pada home industry Dua Putra Jaya di Kabupaten Jombang disimpulkan sebagai berikut:

1. Saluran pemasaran keripik gadung "Dua Putra jaya" terdiri atas saluran tingkat nol, saluran saluran tingkat I dan saluran tingkat II diperoleh sebagai berikut: 

a. Saluran Tingkat Nol
Produsen $\rightarrow$ Konsumen
b. Saluran Tingkat I
Produsen $\rightarrow$ Pengecer $\rightarrow$ Konsumen
c. Saluran Tingkat II
Produsen $\rightarrow$ Pengumpul $\rightarrow$ Konsumen

2. Margin pemasaran pada saluran pemasaran tingkat nol tidak mempunyai nilai margin pemasaran karena hanya melibatkan produsen ke konsumen akhir, untuk saluran pemasaran tingkat I mempunyai margin pemasaran dari produsen sampai konsumen akhir sebesar Rp. 20.000 untuk kemasan 1.000 , sedangkan saluran pemasaran tingkat II mempunyai margin pemasaran dari produsen sampai konsumen akhir sebesar Rp. 20.000 untuk kemasan sebesar 1.000 gram,dan margin total saluran tingkat I sebesar Rp.20.000 dan margin total saluran pemasaran tingkat II sebesar Rp.20.000.

3. Bagian harga yang diterima oleh produsen keripik gadung Dua Putra jaya, pada saluaran pemasaran tingkat nol tidak ada, saluran pemasaran tingkat I sebesar $75 \%$ untuk kemasan $1.000 \mathrm{gr}$ dan saluran pemasaran tingkat II sebesar $55,5 \%$ untuk kemasan $1.000 \mathrm{gr}$.

4. Saluran pemasaran yang paling efisiensi adalah saluran tingkat satu dengan nilai efisiensi sebesar $(31,6 \%)$

\section{DAFTAR PUSTAKA}

Anwar, N., Hadayani, \& Muis, A. 2018. Analisis Pemasaran Keripik Ubi Jalar pada Usaha "Sumber Rezeki" di Kota Palu. Pembangunan Agribisnis, 1(1), 26-34.

Arbi, M., Thirtawati, T., \& Junaidi, Y. 2018. Analisis Saluran Dan Tingkat Efisiensi Pemasaran Beras Semi Organik Di Kecamatan Rambutan Kabupaten Banyuasin. JSEP (Journal of Social and Agricultural Economics), 11(1), 22.

Barat, K. A. 2016. Analisis saluran dan margin pemasaran kue tradisional khas aceh pada ud. meugah di gampong langung kecamatan meureubo.

District, T., \& Regency, K. 2019. Analisis marjin pemasaran keripik ketela ungu di kecamatan tawangmangu kabupaten karanganyar. 3, 568-576.

Fikri, M. S. 2015. Kelurahan Tettikenrarae Kecamatan. 1-71.

Gandhy, A. 2019. Analisis Saluran Pemasaran dan Efisiensi Pemasaran Produk Susu Sapi Perah ( Studi Kasus : Koperasi Produksi Susu Bogor ) Oleh : 43.

Ramlah, S., \& Handayani. 2019. Analisis Pendapatan Dan Pemasaran Cokelat Pada Industri "Sakaya Cokelat" Di Kota Palu. 7(April), 260-266.

Sutoni, A., \& Masrofah, I. 2018. Konsep Pengembangan Inovasi Keripik Gadung, Dalam Pemberdayaan Masyarakat Di Desa Kutawaringin, Kecamatan MandSe, Kabupaten Cianjur. IKRA-ITH Abdimas, 1(2), 71-79 
Aziz, S., Rusman, Y., \& Sudrajat, S. 2014. Halaman | 125. Jurnal IImiah Mahasiswa AGROINFO GALUH, 2(2), 125-130.

Domiah, A. 2016. Analisis Saluran dan Efisiensi Pemasaran Industri Perikanan Tangkap Tuna Skala kecil di kota Bitung, Skripsi. Program Studi Agribisnis Fakultas Pertanian Universitas Jember. 